\title{
GEOGRAFIA DO COTIDIANO: UMA LEITURA DA METODOLOGIA SÓCIO-INTERACIONISTA DE ERVING GOFFMAN
}

\author{
GEOGRAPHY OF EVERYDAY LIFE: AN INTERPRETATION BASED ON \\ THE METHODOLOGY OF SOCIAL INTERACTIONISM OF ERVING \\ GOFFMAN
}

\section{LA GÉOGRAPHIE DU QUOTIDIEN: UNE INTERPRÉTATION DE LA MÉTODOLOGIE DE L'INTERACTIONISME SOCIALE DE ERVING GOFFMAN}

\author{
Ana Helena Correa de Freitas GIL \\ Professora Escola Técnica da UFPR e doutoranda do Programa \\ de Pós Graduação de Geografia da UFPR. e-mail anahgil@ufpr.br \\ Sylvio Fausto GIL FILHO \\ Professor Adjunto Doutor do Departamento de Geografia \\ da UFPR e Membro do Núcleo de Estudos em Espaço \\ e Representações NEER. e-mail faustogil@ufpr.br
}

\section{Resumo}

O estudo do cotidiano envolve a análise do indivíduo de modo geral e as relações com outros indivíduos. O espaço pode ser considerado a base que possibilita a conexão entre as coisas. Sua compreensão está submetida à apreensão imediata do mundo vivido. Para Erving Goffman a vida cotidiana pode ser comparada a um teatro onde os indivíduos desempenham papéis diferentes e interagem com outros indivíduos através dos seus comportamentos físicos e verbais. $\mathrm{O}$ espaço de um bairro é entendido como um palco onde ocorrem diferentes práticas realizadas pelos indivíduos e grupos sociais. Os 
indivíduos são os atores, os sujeitos protagonistas da ação através da interação com as estruturas sociais. Para que ocorra a interação entre os indivíduos é necessário definir os momentos evitando constrangimentos entre os que estão interatuando. No cotidiano as ações dos atores em variados palcos correspondem aos espaços da materialidade da cultura e suas representações. A contribuição desta metodologia para a Geografia Social é a possibilidade de análise integrada das espacialidades do mundo social.

Palavras-Chave: cotidiano, representações, mundo vivido, geografia do cotidiano.

\begin{abstract}
The study of everyday life involves the analysis of the actions of individuals in general and their relations with other individuals. Hereby, space can be considered as the basis which enables the connection between these different elements. Its comprehension is bound to the immediate apprehension of the everyday world. For Erving Goffman, everyday life can be compared to a theater where individuals perform different roles and do interact with other individuals through physical and verbal actions. In this sense, a neighborhood's space can be understood as a stage where are different practices are performed by individuals and social groups. As such, the individuals behave as actors; they are the main protagonists of action building their own social structures. Therefore, specific moments have to be defined which do avoid estrangements between the persons involved. In everyday life, such a staging refers directly to spaces of materiality and their representations. As such, this methodology is a contribution to Social geography paving the way to an integrated analysis on the investigation of spatialities of everyday world.
\end{abstract}

Key-Words: everyday life, lifeworld, representations, geography of everyday life.

\title{
Resumé
}

Une investigation du monde quotidien se refère au tant a l'analyse de l'indvidu en général comme aux relations avec des autres individus. L'éspace est un élément fondamental dans ce context, parceque il rejoint ces élément diférents. Sa compehension est lié a l'apréhension imédiate du monde vécu. Pour Goffman, la vie quotidienne parait un théatre où se recontrent diférents acteurs sur scène exercants ses papiers e agissants avec des autres individus en forme des actions physiques e verbales. Dans ce sense, l'on put comprendre un quartier urbaine comme un théatre, où les individus et groupes sociales sont des acteurs sur scène en base des pratiques spécifiques; de tel forme, ils sont les principales protagonistes pour la formation des leurs propres structures sociales. En conséquence, l'on doit définir des moments spécifiques qui êmpechent un étrangement entre les personnages involvées. Dans la vie quotidienne, une mise-enscène de cet façon se lié directment avec des éspaces de materialité et leurs représentations. Cet métodologie se propose en contribuant pour la géographie sociale comme un chemin qui pave une analyse integrée des espacialité du monde quotidien.

Mot-clés: quotidien, monde vécu, représentations, géographie du quotidien. 


\section{Introdução}

Na cidade, o espaço e a sua forma de organização não é vivenciada nem percebida da mesma maneira pelos indivíduos ou seus grupos sociais, pois cada pessoa vivencia o seu cotidiano de modo específico, possuindo uma diversidade de visões de mundo anteriormente elaboradas e representadas corporalmente através das suas ações no cotidiano. O bairro, como parte do tecido urbano, é ao mesmo tempo fragmentado e articulado no plano social e cultural, assim apresenta profundas desigualdades em relação às suas estruturas construídas. Nas edificações, os indivíduos expressam os seus modos de pensar e; através delas, configuram os seus comportamentos e as suas vivências, fornecendo à cidade uma variedade de formas, todas incorporadas na totalidade urbana, um "conjunto de conjuntos sociais". (BRAUDEL,1998 p. 407).

Já na planta e no corpo construído da cidade podem ser percebidas as representações de uma estrutura que é o produto de regionalizações de longa duração. No entender de Anthony Giddens, isto ocorre através das atividades dos seus moradores. Um grande número de culturas e papéis sociais convive e constrói o seu próprio meio, através de alianças, disputas e conflitos.

Baseado em Munford (1982:38) "a cidade pode ser descrita como uma estrutura especialmente equipada, para armazenar e transmitir os bens da civilização e suficientemente condensada para admitir a quantidade máxima de facilidades num mínimo de espaço.".

Vários elementos sociais podem ser destacados como formadores de elementos urbanos, entre eles a expressão religiosa, a linguagem estilística da arquitetura como sistemas de significação, a organização do sistema de poder e a estruturação do sistema comercial, os dois últimos, como resultado de processos de dominação, no sentido de Giddens ${ }^{1}$ em sua teoria da estruturação.

Cada cidade apresenta sua individualidade, sua formação histórica, sua cultura. Lefébvre (1991, p.47) nos diz que a cidade muda quando a sociedade muda em seu conjunto e, depende também das relações de imediato que se estabelecem (famílias,

\footnotetext{
${ }^{1}$ Ao enunciar a teoria da estruturação, Anthony Giddens remete freqüentemente a exemplos de como ocorre a interação entre individuo e estrutura.
} 
profissões...), mas não só dessas relações imediatas e diretas, mas das relações que ocorrem distante dela, regidas por poderosas instituições como a Igreja e o Estado, que dotados de poder acabam se impondo nas cidades, projetando princípios morais e jurídicos que devem ser seguidos por sua população. "A cidade tem uma história, ela é obra da história, isto é, de pessoas e de grupos bem determinados que realizam essa obra nas condições históricas..."

Sabemos que o estudo da cidade pode ser construído sobre vários enfoques, no entanto, a abordagem adotada será a partir do estudo do comportamento humano em sua situação social. E do modo como os indivíduos ou pessoas aparecem para os outros no seu dia-a-dia, ou seja, em seu espaço do cotidiano.

Certeau (1997) nos fala que:

"O cotidiano é aquilo que nos é dado a cada dia (ou que nos cabe em partilha), nos pressiona dia após dia, nos oprime, pois existe uma opressão do presente. Todo dia pela manhã, aquilo que assumimos, ao despertar, é o peso da vida, a dificuldade de viver, ou de viver nesta ou noutra condição, com esta fadiga, com este desejo. O cotidiano é aquilo que nos prende intimamente, a partir do interior. É uma história a meio-caminho de nós mesmos, quase em retirada, às vezes velados. Não se deve esquecer este "mundo memória”, segundo a expressão Péguy. É um mundo que amamos profundamente, memória olfativa, memória dos lugares da infância, memória do corpo, dos gestos da infância, dos prazeres...”. (p.31)

Como objeto de análise das ciências humanas, o estudo do cotidiano está em grande expansão. Segundo Lefebvre (1991), o cotidiano é uma soma de insignificâncias, não de insignificantes. A banalidade é importante na vida, o levantar, abrir a janela, apreciar o tempo, sentir os sons e os cheiros do dia ao amanhecer. É o banal do dia-a-dia que faz nossa vida ter significado nesse mundo. Devemos também considerar que há graus diferenciados de banalidade. $\mathrm{O}$ autor faz a leitura da vida cotidiana sob uma ótica da racionalidade instrumental, ou seja, para ele o capitalismo colonizou a vida cotidiana, criando uma cotidianidade repleta de significações, de signos, onde o consumo é dirigido e, incentivado pela produção capitalista o que fornece a base de sustentação da constituição do capitalismo em sistema de reprodução de relações sociais de produção. Assim, o cotidiano banal se torna objeto da organização social capitalista.

O estudo do cotidiano compreende a análise do indivíduo de modo geral, envolvido em relações com outros indivíduos. Sendo que o espaço é o meio que possibilita a conexão entre as coisas. Sua compreensão já está submetida à compreensão 
imediata do mundo vivido, que é a soma de todas as ações e intervenções junto ao meio onde o indivíduo vive, criando dessa forma uma experiência de vida, cada qual com a sua experiência.

Na Geografia Humanista-Cultural autores como Tuan, e Buttimer, explicam o mundo vivido muitas vezes diferenciando-o de espaço, como é o caso de Tuan (1990), que afirma que "o espaço se transforma em lugar à medida que o conhecemos e o dotamos de valor". O lugar corresponde a um uso, ou seja, uma prática social vivida. A percepção em relação ao "lugar" é diferente de indivíduo para indivíduo. Betanini (1982) por sua vez, sistematizou as categorias do espaço antropológico, utilizando o termo "espaço vivido" como um espaço que deve ser sentido em "primeira pessoa", onde o indivíduo se sente bem, é o espaço da vida cotidiana. Claval (1995) faz parte da Nova Geografia Cultural e, trabalha o "lugar" como um território comunitário, onde os estilos de vida são semelhantes. Para Buttimer (1969), o vivido não é assumido, ela parte da idéia de visual - portanto de estrutura. Almeida (2003) salienta que o espaço, além de ser produtos das atividades humanas, tem múltiplas valorizações e caracterizase por atributos estruturais, funcionais e afetivos, podendo dessa forma ser considerado como o lugar onde homens e mulheres, ideologicamente diferentes procuram impor suas representações, suas práticas e seus interesses.

Podemos então considerar que o mundo vivido é a conexão entre as coisas e, que o cotidiano pode ser estudado a partir das representações. Mas, o que vem a ser as representações?

É uma forma de conhecimento que de acordo com Moscovici (2003) são um produto da interação e comunicação, sugerindo como campo específico. "O estudo de como e por que as pessoas partilham o conhecimento e desse modo constituem sua realidade comum, de como transformam idéias em práticas” (Moscovici,1990, p.164)

É um olhar da realidade, das relações interpessoais que ocorrem no cotidiano, prendem a atenção, o interesse e a curiosidade das pessoas, fazendo com que muitas vezes haja uma compreensão e pronunciamentos a respeito do que ocorre. Para se chegar a essa articulação, o autor afirma que isso é o "senso comum" de representações sociais verdadeiras e faz parte da vida em sociedade. As representações sociais acontecem em todas as ocasiões e lugares onde as pessoas se encontram informalmente 
e se comunicam, pode ser no ponto do ônibus, na saída das crianças da escola, na lanchonete de uma universidade. Para o autor "as representações sociais, por seu poder convencional e prescritivo sobre a realidade, terminam por constituir o pensamento em um verdadeiro ambiente onde se desenvolve a vida cotidiana.". Trata-se de uma compreensão individual, mas não de indivíduos que pensam sozinhos, eles chegam às conclusões sozinhos, o pensamento é criado, comentado, discutido em grupo. "É a arte da conversação, da troca de experiências, tornarem algo ou alguém não familiar em algo ou alguém familiar.” (Moscovici,1998, p.47) É a tentativa de conceber um universo consensual em um universo reificado. Gil Filho (2005, p.57) comenta que "a análise das representações sociais nos coloca diante da necessidade de decodificar esse mundo próprio do universo banal, o do ser no espaço para o ser enquanto espaço. A espacialidade desse mundo banal possibilita uma Geografia do sendo comum, uma Geografia das Representações”.

Hoje o estudo das representações sociais se orienta à dimensão do imaginário e do afetivo (Zavalloni,1990), superando a dicotomia entre cognição e emoção. Consequentemente, carregada de afeto, as análises voltam-se a participação da memória afetiva-emocional ou reativação da memória, para assim, entender os afetos e assimilar ou criar novos elementos, é o fazer sem entender o saber. Ferrara (2000) salienta que a unidade imagem/imaginário não é outro senão a real percepção da experiência urbana transvertida no uso do espaço e seus lugares. Sendo assim, o estudo das representações sociais assume como ponto de partida para uma Geografia Cultural do mundo banal, da cultura cotidiana.

Vemos então que autores de diferentes áreas estudam de acordo com seu objeto de pesquisa o cotidiano. Dentre eles, podemos destacar a importância e a grande preocupação analítica que caracterizou toda a carreira de Erving Goffman. que voltou suas análises a vida cotidiana de pequenos grupos.

Devemos então, contextualizar o autor para entendermos como desenvolveu sua teoria e de que modo iremos aplicá-la na geografia do cotidiano. 
Erving Goffman, filho de imigrantes judeus, nasceu no Canadá em 1922, foi um jovem rebelde, que ao assistir uma produção "Canadá para Canadenses" começa a refletir sobre as representações que acontecem no palco e na tela de cinema. Ele cursou a faculdade de química em 1939 e só em 1944 tem a oportunidade de cursar Sociologia. Fortemente influenciado pelos ideais de Durkheim, chega a concluir que o "todo está determinado socialmente" e, que a "sociologia pode mudar a sociedade". O estudo de um objeto deve ser considerado como um sistema em si mesmo (cara a cara), tendo como base o funcionalismo. A sociedade é constituída de interações que ocorrem pela linguagem e pela conduta. Goffman não só descreve mais analisa as interações sociais dos sujeitos por meio da linguagem, gestos, olhares e verbalização. Utiliza desse modo, a metáfora teatral, por considerar as pessoas como atores e define as atuações dos indivíduos em suas interações, como se tratasse de uma obra de teatro. O método adotado é o monográfico, ou seja, o estudo de caso em profundidade, sempre de pequenos grupos. O olhar é o das observações das representações das pessoas. Em 1982, o autor falece deixando um legado teórico metodológico de inestimável importância, sendo utilizado em diversas áreas como psicologia social, psiquiatria, sociologia, lingüística aplicada, direito e atualmente na geografia entre outras.

Dentro desta perspectiva, Goffman abriu espaço teórico para o aperfeiçoamento de métodos de pesquisa em geografia, enfocando, sobretudo a interação social como forma de construção de significados, partindo da observação de pessoas ou grupos de pessoas por meio de suas representações. O pesquisador pode assim, considerar ambientes onde ocorram interações sociais, detalhando o comportamento humano e os significados dos mesmos relacionando-os e comparando-os a outros grupos.

\section{A Geografia do cotidiano}

A geografia do cotidiano é a geografia do modo de ser, fazer, representar, numa visão do olhar das pessoas que vivem, passam ou habitam um bairro de uma cidade. Pelo fato do seu uso habitual, o bairro pode ser considerado como a privatização progressiva do espaço público. (CERTEAU, 1997).

É o estudo do "mundo vivido" de indivíduos ou pequenos grupos. Podemos considerar o bairro, como um lugar onde ocorrem relações diferenciadas entre as 
pessoas, onde ocorrem diferentes tipos de especialidades e temporalidades. Essas percebidas de formas distintas entre os grupos sociais que há compõem, pois cada um vivencia o seu cotidiano de modo especifico, possuindo uma diversidade de visões previamente elaboradas e apresentadas corporalmente através de suas ações no mundo banal. A prática de um bairro favorece a ocupação do espaço urbano, o público acaba se tornando o privado devido a trivialidade cotidiana partilhada pelos usuários.

Nessa geografia do cotidiano existem cenários de interação no espaço público, o que Goffman considera como a representação teatral, partindo do caráter dramatúrgico, é a maneira com que o indivíduo se apresenta, em situações comuns como trabalho e o lazer a outras pessoas. Podendo para isso utilizar diferentes tipos de fachadas. O palco são lugares do cotidiano, conhecidos ou não dos atores. Nesse palco, várias máscaras servem para ajudar no desempenho na área de atuação. Sendo assim, propomos uma análise da geografia do cotidiano sob um enfoque goffmaniano, permeando idéias de Benno Werlen (1993), que toma como ponto de partida um sujeitoator como protagonista da ação e da interação nas estruturas sociais e de como a representação influência a ação. E de Stanislaviski (2005), que sistematiza em seus livros os conhecimentos intuitivos de grandes atores em base de suas experiências do passado re-apresentadas no presente, embutindo o ator num agir contemporâneo que representa uma criação ou realização estimuladora na interação social. Também Michel Mafessoli (1999), que contribui na discussão, ele aponta para a função do processo criador como expressão social como um "nascimento", um "desenvolvimento" e uma "morte" dos elementos que caracterizam a sociedade. Enfatizando as diversas modulações da aparência que formam um conjunto social. $\mathrm{O}$ autor considera as teatralidades cotidianas como um vetor de conhecimento, uma alavanca metodológica de importância para a compreensão humana e, que de forma alguma pode ser encarada como uma frivolidade.

Segundo MAFFESOLI (1999, p.155):

"De fato, a prevalência da aparência é, de um lado, uma realidade ( um conjunto de realidades) suficientemente verificada para que seja levada a sério. E, do outro, uma constante antropológica que se encontra em lugares e em tempos diversos. Isso também é preciso lembrar. A teatralidade dos corpos que se observa hoje em dia é apenas a modulação dessa conduta: a forma esgota-se no ato, é pura eflorescência, basta-se a si mesma. Inúmeros são os domínios onde isso é observável. Nos que fazem disso profissão, com certeza da moda à publicidade, passando pelas diversas imagens midiáticas. Mas o político não escapa a isso, assim como as estratégias econômicas." 
A imagem está onipresente no social, ao chegarmos à presença de outros a primeira observação é a da aparência, o estar - social. Portanto, o estudo do cotidiano pode nos levar a conhecer a expressão de cada sociedade. Através da fenomenologia compreensiva podemos procurar entender um pouco mais sobre como se exprime cada sociedade através de suas modulações da aparência e "modos de ser". De fato, a vida cotidiana se organiza por meio de imagens, de uma inteligência imaginativa, aquela que é entendida por meio de curvas, linhas, modulações, entre outros, como algum objeto como um sofá, uma cadeira, uma montanha. Reconhecida pela sociedade e ao mesmo tempo constituindo uma cultura local expressa como uma forma de arte que pode ser Esse conceito de espaço estimado pela Geografia é extremamente universal. Sua compreensão já está submetida à compreensão imediata do mundo e Esse conceito de espaço estimado pela Geografia é extremamente universal. Sua compreensão já está submetida à compreensão imediata do mundo e a e explorada.

\section{Metodologia Sócio- Interacionista de Erving Goffman}

O autor parte de análises sobre a vida cotidiana das pessoas, ou seja, como o indivíduo ou pequenos grupos se apresentam em diversas situações comuns do cotidiano, o trabalho, o lazer entre outros. Como age, como se comunica os meios pelos quais dirige e regula as impressões sobre si quando ocorrem as interações. Os princípios utilizados são os da dramaturgia e da representação. Goffman parte do princípio de que quando um indivíduo desempenha um papel ele solicita de seus observadores que levem a sério a impressão sustentada por ele, acreditando no que estão observando e, que a representação está sendo realizada para benefício de quem está assistindo ou participando, o espetáculo é dado para benefício dos outros. Nesse espetáculo temos atores sinceros e cínicos. O sincero é aquele compenetrado inteiramente em seu número, na sua representação, está convencido de que a impressão de realidade que encena é a verdadeira realidade. Por sua vez, o cínico é aquele que não está compenetrado em sua própria prática, muitas vezes não se interessando pelo que o público acredita o indivíduo não crê na sua própria atuação, há um descompromisso, pode brincar com alguma coisa que o público deva levar a sério. Goffman afirma que nem todos os atores "cínicos" 
querem iludir sua platéia para seu benefício. Alguns casos como o de médicos que são levados a receitar medicamentos inócuos aos pacientes para tranqüilizá-los, ou o garçom que traz pepsi-cola ao invés de coca-cola porque tem o mesmo gosto e na verdade é porque o representante de bebidas só trouxe pepsi, são profissionais cínicos, cujo público não lhes permitiria usar da sinceridade.

Nesse sentido, a metodologia de Goffman pode ser aplicada no estudo do cotidiano de um bairro de uma cidade, podemos identificar os atores sociais e seus grupos no processo de estruturação do cotidiano, bem como perceber de que modo os indivíduos são influenciados em suas ações pelas representações assumidas.

Para desempenhar um papel o indivíduo ou pequenos grupos precisam ter um cenário par compor e dar força ao desempenho na atuação. $\mathrm{O}$ cenário normalmente compreende a mobília, a decoração, a disposição física e outros elementos que darão sustentação para a representação. Geralmente o cenário é fixo, somente em circunstâncias especiais o cenário acompanha o ator, por exemplo, no caso de uma manicure que atende nas casas, um torneiro mecânico, um pedreiro...Todos esses elementos servem para formar a fachada empregada durante a representação.Segundo o autor às vezes é conveniente dividir os estímulos que formam a fachada pessoal em "aparência" e "maneira". A aparência nos revela o status social do ato e, a maneira nos informa sobre o papel do ator. Todos esperam que haja uma compatibilidade entre aparência e maneira. Em um bairro, se o indivíduo vai consultar com um médico espera encontra-lo com sua tradicional roupa branca, limpa, utilizando uma linguagem apropriada aos médicos, se ao contrário encontrar o médico mal arrumado, com unhas e cabelos longos provavelmente terá uma impressão ruim e não acreditará no diagnóstico prescrito. Maffesoli (1994) considera que muitas vezes as pessoas julgam pelas aparências esquecendo-se da essência, mesmo assim deveria existir coerência entre ambos. A aparência é o que se deixa ver, é uma realidade que pode ser verificada por meio do aspecto figurativo do mundo social. Quando o indivíduo assume um papel, sua fachada já está elaborada, ele deve então assumi-la, é o caso dos políticos, dos vendedores, dos médicos, dos professores, das empregadas domésticas, enfim cada um tem um papel que será desenvolvido e a fachada já está pronta. Faz parte dessa fachada a roupa e os equipamentos necessários para realizar a representação. Maffesoli (1994) salienta que "A roupa tem a conotação de habitus que supõe um trabalho sobre o 
corpo". Devemos lembrar que o conceito habitus adotado por Mafessoli difere do de Bourdieu (1997) que introduziu a idéia para descrever como valores coletivos instruem e até prefiguram, comportamentos individuais em instituições sociais, como escolas e mídias de massa. Os habitus são ao mesmo tempo diferenciados e diferenciadores. $\mathrm{O}$ autor argumenta que "o mesmo comportamento ou o mesmo bem pode parecer distinto para um, pretensioso ou ostentatório para outro e vulgar para um terceiro. Já Durkheim lembra que toda a sociedade tem um conformismo moral, entendendo conformismo como conformidade dos costumes, uma imitação na vida social, uma conjunção roupahábito. A aparência social serve muitas vezes como uma espécie de proteção eficaz, são os uniformes, o guarda-pó, o jaleco, a aparência das moças maquiadas em lojas de perfumes, cosméticos e jóias. O indício da aparência tem certa comodidade, certo segurança. No entanto, não podemos nos esquecer de que nem sempre o que vemos é a realidade verdadeira, é a que nos é apresentada, mas pode não ser verdadeira. A familiaridade com o papel a ser desempenhado faz com que o ator desempenhe seu papel com total segurança, a roupa, a linguagem utilizada, tudo faz parte da fachada que será assumida, o ator já tem a fachada pré-estabelecida. Como exemplo, pode citar o político do bairro, ele já tem um discurso pronto, tudo será realizado para transformar o bairro em um dos melhores da cidade, para tanto ele, conta com o apoio da população, apertos de mão, abraços, crianças no colo, sorrisos e palavras de atenção são característicos do papel que estará executando. Na presença de outros com certeza o indivíduo inclui uma série de sinais que acentuam e configuram de modo impressionante os fatos que deverão ser confirmatórios em sua atuação. Desse modo, podemos caracterizar os cenários e as representações sociais na vivência cotidiana de um bairro

Outro ponto que Goffman considera é que o indivíduo adota diferentes fachadas para executar sua representação. Assim, um profissional pode desempenhar um papel modesto, auxiliando os vizinhos em uma limpeza comunitária do bairro, mas como profissional pode ser um juiz conceituado e adotar outro tipo de fachada, incorporando e exemplificando os valores oficialmente reconhecidos pelos indivíduos da sociedade. De fato, as impressões têm um aspecto idealizado, devem ser reconhecidos pela platéia que assiste ou interage. Se o indivíduo quer dar expressão a padrões pré-estabelecidos precisa abandonar ou esconder ações que não lhe sejam 
compatíveis.Os atores podem até passar a impressão de que sempre tiveram determinada eficiência e equilíbrio e, que não foi necessário um aprendizado. Quando nos é apresentada uma fachada falsa, ou temos a impressão de que a impressão adotada não é verdadeira, sentimo-nos ameaçados. O autor comenta que "quanto mais estreitamente a representação do impostor se aproxima da realidade tanto mais intensamente podemos estar ameaçados, pois uma representação competente feita por alguém que demonstra ser um impostor pode enfraquecer nosso espírito, a autorização legítima para desempenhar um papel." Estudantes que agem como se já fossem formados, indivíduos que clinicam sem ter diploma, político que fala uma coisa no discurso e na prática faz outra coisa., a representação pode acentuar alguns aspectos e dissimular outros.A platéia pode perceber os mistérios mas em respeito ao ator permanecer em silêncio. Muitos atores acreditam sinceramente que a situação que estão representando define a situação verdadeira e, é a realidade verdadeira. Ou seja, assumem o papel e se colocam como atores sinceros. No mundo real a sinceridade, a honestidade faz a representação honesta. Já no teatro o treinamento, a capacidade de incorporar o papel pode transformar o ator na sua encenação dramática pode fazer com que um papel ganhe vida. Podemos então, avaliar as performances dos atores sociais na dinâmica do bairro, bem como relacionar os diferentes cenários formando a complexidade do bairro.

Sranislaviski (2005) afirma que para a criação de um personagem é necessário usar o corpo, a voz, o modo de falar, de andar, de mover, senão houver uma caracterização que corresponde à imagem, jamais poderia ser transmitido ao público o espírito interior vivo, o traçado interior do papel. É necessário abrir a imaginação e começar a existir na vida imaginária, assim percebem-se mais nitidamente os sentimentos de outras pessoas, as relações com elas e as delas para conosco. Só assim é possível tornar-se plenamente envolvido na ação imaginária, como o autor coloca "mover-se entre fantasmas da sua imaginação e comunicar-se com elas, será capaz de dar vida às circunstâncias externas e internas." Nessa relação de vida cotidiana com encenação dramática Goffman faz a leitura do mundo vivido, dos "eus" que cada um representa e apresenta. São os "eus" que se formam a cada dia, o processo é longo. Goffman se preocupa em ir além das representações teatrais apresentadas no cotidiano, ele analisa as representações dentro das interações - dos encontros sociais. A 
representação tanto no teatro como na vida real implica situações e uso de técnicas verdadeiras, as quais o autor destaca que na vida diária, essas mesmas técnicas mantêm situações sociais reais. Dentro dessa metodologia adotada por Goffman a geografia do cotidiano pode ser estudada admitindo-se uma tentativa de articular diferentes cenários da totalidade do espaço urbano.

\section{Considerações Finais}

Para se compreender o comportamento humano é preciso conhecer a natureza do indivíduo e dos grupos sociais dos quais faz parte. Que papéis os indivíduos desempenham, quando e em que condições se formaram, bem como quais foram as condições em que se formaram, entre outras questões. Nessa perspectiva, Ervin Goffman mostra-nos uma abordagem do estudo do cotidiano sob uma ótica da dramaturgia. Para a geografia social a metodologia adotada pelo autor é uma grande contribuição no sentido de se analisar as representações sociais na estruturação do cotidiano de um bairro a partir de sua situação social.

Nesse contexto podemos levantar as seguintes possibilidades metodológicas sobre a aplicação da abordagem a de Erving Goffman na geografia social:

- Identificação dos grupos sociais e suas representações no uso e ocupação de um bairro e sua estruturação no cotidiano;

- Contextualização dos grupos sociais em seus cenários que definem as espacialidades de um bairro;

- O mundo vivido como dimensão da expressão das práticas sociais cotidianas a partir das espacialidades de um bairro;

- Avaliação das performances dos atores sociais na dinâmica de atuação em espacialidades diferenciadas (sinceros e cínicos)

- A percepção da estruturação do cotidiano a partir das representações de seus atores; bem como os indivíduos são influenciados em suas ações pelas representações assumidas;

- A caracterização da compatibilidade das espacialidades do cotidiano a partir de grupos sociais e indivíduos em relação a aparência e maneira; (descrição no 
sentido de Garfinkel ou seja estabelecer uma correspondência entre a norma e o caso concreto)

- A verificação de conformidade ou diferenciação dos costumes dos indivíduos e dos grupos sociais em suas práticas cotidianas na estruturação das espacialidades.

Os tópicos apresentados propiciam uma ponte teórico-metodológica entre a abordagem sócio -interacionista de Erving Goffman e a constituição das espacialidades do cotidiano principalmente no que tange ao estudo da cidade e os recortes privilegiados da vizinhança sintetizadas no bairro. Acreditamos no desenvolvimento de estudos a partir da teoria das representações goffmaniana, no âmbito da geografia social, como resposta privilegiada as questões críticas que o devir nos coloca. Trata-se de um recurso interessante para uma segunda hermenêutica do cotidiano através da configuração das espacialidades como cenários interativos das praticas sociais de indivíduos e grupos.

\section{Referências Bibliográficas}

ALMEIDA, M.G. "Espaço em busca do poético do sertão: um estude de representações”. In ALMEIDA, M.G. \& RATTS, A. J.P. (orgs.) Geografia Leituras Culturais. Goiania : Aletrnativa, 2003.

BALANDIER, G. Essa $d^{\prime \prime}$ identificacion du quotidien. Cahiers Internationaux de Sociologie. Paris : PUF,v.LXXIV, 1983

BENEVOLO, L. A cidade e o arquiteto, São Paulo: Martins Fontes, 1984.

, História da arquitetura moderna, São Paulo: Perspectiva, 1994.

BOURDIEU, P. O Poder simbólico, Rio de Janeiro: Bertrand Brasil, 1998.

, Razôes Práticas sobre a teoria da ação, São Paulo: Papirus, 1997.

BUTTIMER, Social Space in Intersdiciplinary Perspective. Geographical Review,v.59 n.4,1969-p.417-26

CARLOS, A.F.A. O lugar no/do mundo, São Paulo: Hucitec, 1996.

CARTWRIGHT, D.; ZANDER, A. Dinâmica de Grupo. $3^{\text {a }}$ Ed. São Paulo: EPU, 1967. 
CERTEAU, M., A invenção do cotidiano - Artes de Fazer, Petrópolis, Vozes: 1999.

CERTEAU, M. GIARD L. e MAYOL P. A invenção do cotidiano - Morar e Cozinhar, Petrópolis, Vozes: 1997.

CLAVAL, P. A Geografia Cultural Florianópolis: Ed. UFSC, 1989.

CORRÊA, R.L., O espaço urbano, São Pau lo: Ática,1993.

CORRÊA, R. L. \& ROSENTHAL, A. Paisagem, Tempo e Cultura, Rio de Janeiro: UERJ, 1998.

__, Introdução a Geografia Cultural, Rio de Janeiro: Bertrand Brasil, 2003.

_., Geografia: Temas sobre cultura e espaço: Rio de Janeiro, Eduerj, 2005.

DURKHEIM, E. Lês formes élementaires de l avie religieuse. Op. Cit. , 24-25 Sobre o espetáculo, cf G. Debord, La soiété du spectacle, Paris, 1967, e Commentaire sur la Socié té du spectracla, 1988.

FERRARA, D.A. Os significados urbanos. São Paulo: Edusp/ Fapesp, 2000.

GARFINKEL, H. Studyes in ethnometodology. Englwood Clifsd: Hall, 1967

GIDDENS, A. A. , A Constituição da Sociedade, São Paulo: Difel, 1983.

_. The Consequences of Modernity, Cambridge: Polity Press, 1985.

GIL Filho, S.F. Geografia Cultural: Estrutura e primado das Representações, Rio de Janeiro: UERJ,NEPEC,DEZ,1996.

GOFFMAN, E. A representação do eu na vida cotidiana, Rio de Janeiro: Vozes, 1975.

LEFEBVRE,H., Tiempos Equívocos, Barcelona: Editorial Kairós, 1976.

, O Direito à Cidade, São Paulo, Moraes, 1991.

-----. A vida cotidiana no mundo moderno. São Paulo: Ática,1991.

MACHADO, L. M.C.P. , Paisagens Valorizadas: A serra do Mar como espaço e lugar. In: RIO, Vicent del; OLIVEIRA, L. (Org). Percepção ambiental: a experiência brasileira. 2 ed. São Paulo: Studio Nobel, 1999, p. 97-98.

MAFFESOLI, M. No fundo das aparências, Petrópolis: ed Vozes, 1999.

MOSCOVICI, S. Prefácios de textos em Representações Sociais in GUARESCHI.P. \& JOVCHELOVITCH (orgs)Textos em Representações Scoais. Petrópolis: Vozes, 1998.

Vozes, 2003

Representações Sociais - Investigações em psicologia Social. Petrópolis: 
MUNFORD, L. A cidade na História: São Paulo: Martins Fontes, 1998.

LYNCH, K. A Imagem da Cidade, Lisboa: Edições 70, 1960.

SANTOS, M. A Urbanização Brasileira, São Paulo: Hucitec, 1993.

A natureza do espaço, São Paulo: Hucitec, 1996

__,Espaço e Método, São Paulo: Hucitec, 1996.

STANISLAVSKI, C., A construção da personagem, Rio de Janeiro: Civilização Brasileira, 2005.

A criação de um papel, Rio de janeiro: Civilização Brasileira, 2005.

ROUBINE, J.J., A arte do autor, Rio de Janeiro, Ed. Jorge Zahar Editor LTDA, 1990.

TEDESCO, J.C. Paradigmas do Cotidiano,EPF Editora, 2003.

TUAN, Yi-Fu, Topofilia: Um Estudo da Percepção, Atitudes e valores de meio Ambiente, Trad. Lívia de Oliveira, São Paulo: Difel/ Difusão Editorial S/A, 1980.

ZAVALLONI, M. Tha affective represesentation circuit as the foundation of identtity in new ideas psych. In: New Ideas in Psychology, 4:333-45, 1996.

Recebido para publicação em maio de 2008 Aprovado para publicação em junho de 2008 